\title{
Genetic Characterization of Taiwan Commercial Native Chickens Ascertained by Microsatellite Markers
}

\author{
Manh-Hung Pham ${ }^{1,2}$, Wei-Hua Chang ${ }^{1}$, Cécile Berthouly-Salazar ${ }^{3}$, Der-Yuh Lin ${ }^{4}$, \\ Sukanya Yungrahang ${ }^{1,5}$, Chien-Chan Wang ${ }^{6}$, Yen-Pai Lee ${ }^{1}$, \\ Michèle Tixier-Boichard ${ }^{7}$ and Chih-Feng Chen ${ }^{1,8}$ \\ ${ }^{1}$ Department of Animal Science, National Chung-Hsing University, Taichung, 40227, Taiwan \\ ${ }^{2}$ Department of Animal Breeding and Genetics, Institute of Animal Sciences for Southern Vietnam, \\ Go Vap District, Ho Chi Minh City, Vietnam \\ ${ }^{3}$ Centre for Invasion Biology, Stellenbosch University, Private Bag XI, Matieland 7602, South Africa \\ ${ }^{4}$ Division of Breeding and Genetics, Livestock Research Institute, COA, Tainan, Taiwan \\ ${ }^{5}$ Department of Animal Science, Kasetsart University, Kamphaeng Saen Campus, Thailand \\ ${ }^{6}$ Shih Kong Chao Feng Ranch and Resort, Hualien 975, Taiwan \\ ${ }^{7}$ INRA/AgroParisTech, UMR1313 Animal Genetics and Integrative Biology, Jouy-en-Josas, France \\ ${ }^{8}$ Research Center for Integrative and Evolutionary Galliformes Genomics (iEGG), \\ National Chung-Hsing University, Taichung, 40227, Taiwan
}

\begin{abstract}
Taiwan commercial native chickens have played a vital role in the domestic market due to Taiwanese traditional cooking style and culture. This study investigated the genetic characterization and population structure of 10 Taiwan commercial native chicken populations, together with two exotic breeds and one population of red jungle fowl, using 22 microsatellites. The results showed that Taiwan commercial native chickens generally harbored high genetic diversity but lower than that of red jungle fowl population in terms of number of alleles and gene diversity. The neighbor-joining tree revealed a poor resolution with only two branches showing bootstrap values above $70 \%$. Based on Bayesian clustering approach, thirteen populations were inferred into eight distinct clusters namely Game bird, B strain, L2 strain, White Broiler and White Leghorn with an average proportion of membership higher than 0.90 and the values higher than 0.85 for red jungle fowl, Hakka chicken and Hakka strain while four remaining breeds were closely related together. The population structure showed Taiwan commercial native chickens are more admixed, in contrast to occidental highly productive breeds. The high genetic variation within breed as shown in the results of the analysis of molecular variance, facilitated by gene exchanges, did not allow discriminating in an efficient way. This suggests that the genetic pool of Taiwan commercial native chickens is well distributed among breeds and therefore there is a good potential for adaptation to new environmental conditions or markets. Some populations, namely L2 strain and B strain showed very high inbreeding coefficient and thus could be considered at risks. Therefore, management needs to be taken into account for the populations, to prevent inbreeding depression and maintain genetic diversity.
\end{abstract}

Key words: Bayesian clustering approach, genetic diversity, microsatellite, population structure, Taiwan

$$
\text { J. Poult. Sci., 50: 290-299, } 2013
$$

\section{Introduction}

Chicken meat and egg play an important role in Chinese traditional cuisine in Taiwan. There was 40 to $50 \%$ chicken meat from imported exotic White broiler (USDA, 2006) while the remaining meat production comes from Taiwan

Received: March 25, 2012, Accepted: March 7, 2013

Released Online Advance Publication: April 25, 2013

Correspondence: CF. Chen, Department of Animal Science, National Chung-Hsing University, Taichung, 40227, Taiwan.

(E-mail: cfchen@dragon.nchu.edu.tw) commercial native chickens (TCOM). For instance, Red feathered and Black feathered chickens produce about $80 \%$ of TCOM and the remaining $20 \%$ comes from commercial slow-growing local breeds such as Silkies, Naked Neck, Game bird, Hakka chicken, Golden chicken and Classical chicken (Lee, 2006). Taiwan native chickens were frequently crossed with imported exotic breeds (broiler-type rooster) to produce TCOM and selected by local farmers for high body weight, feed efficiency and their ability to adapt to local conditions since 1960s (Lee, 2006).

Genetic diversity of chicken genetic resources provides the 
basis for genetic improvement in order to increase productivity but also to adapt domestic populations to changes in production environments as well as in markets, management practices, and disease challenges (Tixier-Boichard et al., 2009; Boettcher et al., 2010). Moreover, the understanding of the constitution of breeds, effective management and traceability of breed origin is needed for potential utilization their genetic resources (Dalvit et al., 2007; Nakamura et al., 2010).

Population structuring might reflect the management status and breeding histories of chickens. Using 18 microsatellite markers, Berthouly et al. (2009) recently reported that the scavenging Vietnamese Ha Giang chicken breed was highly variable and in some localities even exchanged genes with the wild relatives, red jungle fowl. In contrast, the study of six Taiwan native chicken breeds under a conservation program at Chung-Hsing University (NCHU) showed breed specific features with a multi-criteria approach combining 24 microsatellite markers, the melanocortin 1 receptor $(M C 1 R)$ locus, a major histocompatibility complex (MHC) marker and phenotypic data (Chen et al., 2004; Chen et al., 2005; Chang et al., 2012). Similarly, Takahashi and Nakamura (2007), using 24 microsatellites, suggested that four strains of the Nagoya breed were highly differentiated. These four Nagoya strains were established for egg and meat production since many years in Japan.

Taiwan commercial native chickens have been developed by local farmers for improvement of production efficiency as well as meat quality, but little information on their genetic relationships and population structuring is known. This research aims to investigate the genetic characterization and population structure for Taiwan commercial native chicken breeds.

\section{Material and Methods}

\section{Populations}

The TCOM have prevalently appeared to have a big erected comb, blue shanks, big legs, and a smaller breast with less fat under skin than exotic broiler, and produce small eggs but with larger proportion of yolk. They grow faster than native chickens (i.e., Hua-Tung, Hsin-Yi, Ju-Chi and Quemoy) and are preferred by Taiwanese consumers because its meat quality suits to the traditional cooking style and similar plumage color compared to Taiwan native chickens (Lee, 2006). Red feathered chicken was developed in early 1980's through continuously introgression of imported exotic breed into the small Red feathered chicken and selection for early maturity and production efficiency. The smaller body-size Black feathered chickens with white hackles were developed by farmers in Changhua County in the late 1980's. In recent years, Golden chickens were produced by crossing Red feathered male with Black feathered female. Simultaneously, Classical chickens with red-black plumage and strong shanks were also created. Game bird was a fighting chicken and local farmers only used hens and capons for food consumption.

Conservation of native chickens in Taiwan started from
1982, when native chickens were collected around the islands and conserved at NCHU. In the same year, this university began to establish chicken lines for specialized purposes. Both L2 and B strains were selected by NCHU from the same Taiwan native chicken population (Lee, 2006). L2 and B strains have now been selected for 24 and 26 generations, respectively, and have been extensively used in research as well as in production (Chao and Lee, 2001; Chen et al., 2007). Both strains were closed populations since their establishment in 1983 while B strain was a male line and L2 was female line for crossing to produce commercial meattype chicken. L2 strain has higher egg production, but B strain is better for meat production after a long-term selection (Chen et al., 2007). Likewise, Hakka people preferred large chickens so their chickens had low egg production (Lee, 2006). Thus, NCHU used Hakka chicken sires crossed with L2 strain dams to establish the synthetic Hakka strain in order to improve its egg performance since 2005.

\section{Sampling and Genotyping Microsatellite}

A total of 493 chickens from 10 Taiwan commercial native chicken breeds, two exotic breeds and one population of red jungle fowl with pure white earlobes (G. g. gallus type C) inhabiting in the continental Southeast Asia (Nishida et al., 2000; Nishibori et al., 2005) kept in Taiwan were analyzed together. Red jungle fowl (JF, $n=22)$ came from Hualien preserved station (Fig. 1). Two exotic highly productive breeds were: a parent stock of White broiler (BR, $n=24)$ and of White Leghorn (LG, $n=54)$. Ten TCOM were investigated: B strain (BS, $n=45)$, L2 strain (LS, $n=51)$ and Hakka strain (HS, $n=27$ ) conserved at NCHU experimental farm; Hakka chicken ( $\mathrm{HC}, n=45$, from one farm), Black feathered (BF, $n=46$, from three farms), Red feathered (RF, $n=49$, from three farms), Golden chicken (GC, $n=13$, from one farm), Classical chicken (CC, $n=26$, from one farm), Game bird (GB, $n=42$, from two farms) and Naked Neck (NN, $n=49$, from two farms). The required laws and regulations regarding the use of chickens have been followed in scientific research. Blood samples were taken from the wing vein into the sterile blood collection tubes (BD Vacutainer, Franklin Lakes, NJ USA) containing 7.2 mg K2 EDTA and stored at $4^{\circ} \mathrm{C}$ and subsequently genomic DNA was extracted using the salt extraction method (Miller et al., 1988) and stored at $-20^{\circ} \mathrm{C}$. Twenty two microsatellite markers distributed on 12 autosomal chromosomes (Table 1) previously used in the AVIANDIV project were chosen for genotyping 493 individuals. These all 22 markers were polymorphic in 52 chicken populations from different management practices and breeding histories (Hillel et al., 2003). PCR products were analyzed by 3730 DNA Analyzer of Applied Biosystems and genotypes were read using GENEMAPER version 4.0.

\section{Data Analysis}

The presence of null alleles was tested using FreeNA software (Chapuis and Estoup, 2007) in which loci with the estimated frequencies of null alleles $(\mathrm{r} \geqq 0.2)$ were considered to be potentially problematic for calculations. The number of alleles, effective number of alleles (Weir, 1990) and 


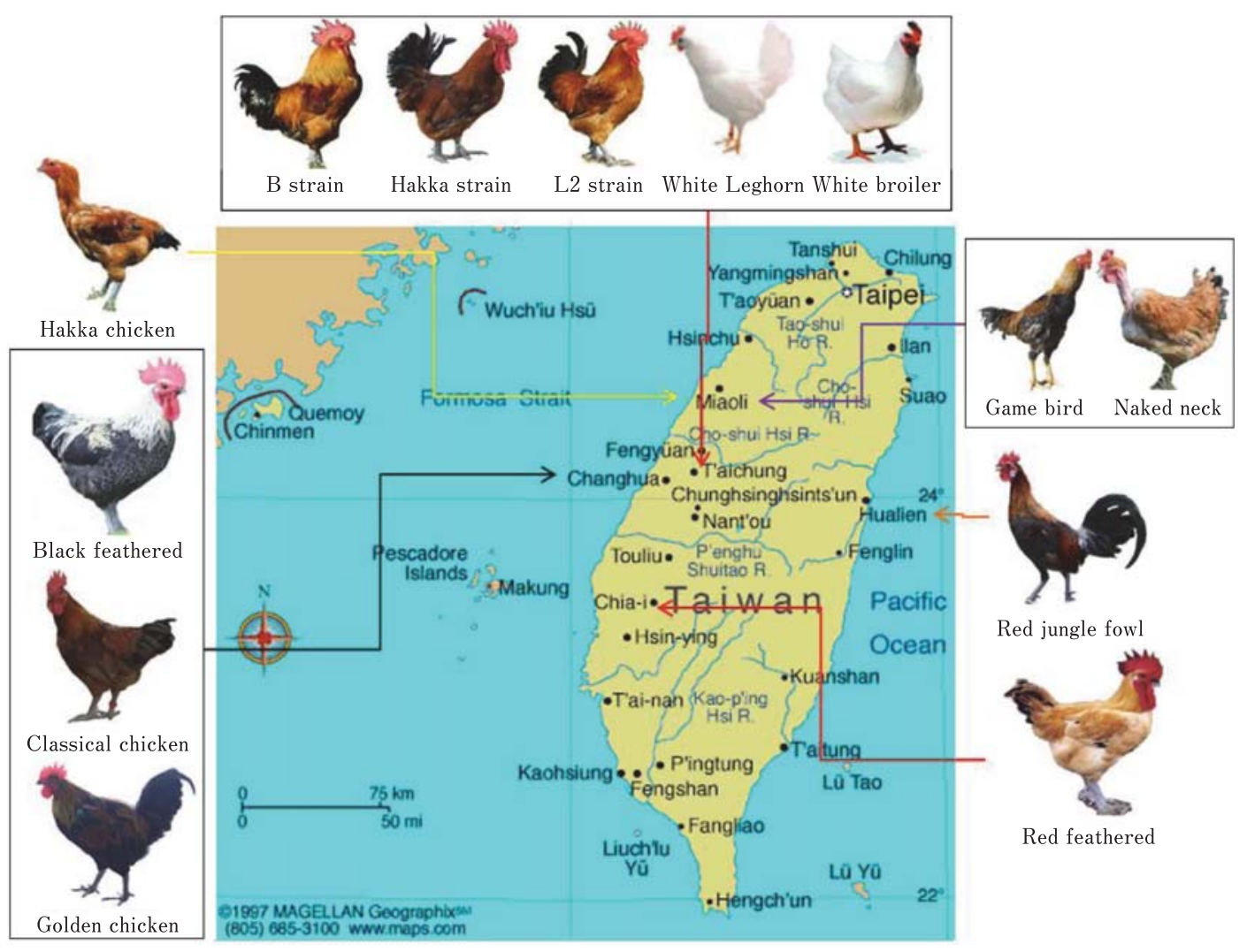

Fig. 1. The distribution of $\mathbf{1 0}$ Taiwan commercial native chicken populations, two exotic breeds and one red jungle fowl population all over the country. B strain (BS), L2 strain (LS), Hakka strain (HS), Hakka chicken (HC), Black feathered (BF), Red feathered (RF), Golden chicken (GC), Classical chicken (CC), Game bird (GB) and Naked Neck (NN); White broiler (BR) and White Leghorn (LG); red jungle fowl (JF). This map was obtained from http://www.infoplease.com/atlas/country/ taiwan.html (Accessed on November 9, 2011).

private alleles were calculated by GENALEX 6.41 package (Peakall and Smouse, 2006). The observed heterozygosity, expected heterozygosity and Polymorphic Information Content (PIC) values (Botstein, 1980) were performed by the CERVUS version 3.0.3 (Kalinowski et al., 2007). Moreover, the $F_{\text {IS }}$ values according to Weir and Cockerham (1984) and exact test for deviation from Hardy-Weinberg equilibrium (HWE; Guo and Thompson, 1992) were computed by the GENEPOP software version 4.1 (Rousset, 2008). Allelic richness (AR), using a rarefaction method, was estimated with FSTAT 2.9.3 (Goudet, 2002).

The modified Cavalli-Sforza chord distance $D_{\mathrm{A}}$ (Nei et al., 1983) and Reynold's genetic distance $D_{\mathrm{R}}$ (Reynolds et al., 1983) were computed by the POPULATIONS package 1.2.32 (Langella, 1999). The phylogenetic tree was constructed using neighbor-joining (NJ) clustering method (Saitou and Nei, 1987) based on pairwise genetic distances $D_{\mathrm{R}}$ (Reynolds et al., 1983) for the 13 populations by the PHYLIP version 3.69 (Felsenstein, 2009). Bootstrap resampling values of 1,000 was performed to test the robustness of the tree topology. Analysis of molecular variance (AMOVA) was computed using ARLEQUIN version 3.5.1.2 (Excoffier and Lischer, 2010) and variance components were estimated among and within the population groups.

Additionally, ten TCOM populations, two exotic breeds and one red jungle fowl population were used to investigate the genetic structuring between populations. The Bayesian clustering method implemented in STRUCTURE 2.3.3 (Pritchard et al., 2000) was performed with admixture model and with correlated allele frequency to infer the population structure (Falush et al., 2003) on the BIOPORTAL (Kumar et al., 2009). In the first step, we ran Structure from $K=1$ to $K=16$ as the number of assumed genetic clusters, 50 independent runs for each $K$ value with $1 \times 10^{6} \mathrm{MCMC}$ iterations after a burn-in period of $5 \times 10^{5}$ repetitions. The evaluation of the best $K$ genetic cluster was based on $\Delta K$ from $K=2$ to $K=15$, 50 runs each $K$ value following Evanno method (Evanno et al., 2005) using STRUCTURE HARVESTER v0.6.91 application (Dent and Bridgett, 2012). Then CLUMPP 1.1.2 (Jakobsson and Rosenberg, 2007) was used 
Table 1. The profile of 22 microsatellite markers, allele range (bp), annealing temperature $\left(T_{\mathrm{A}},{ }^{\circ} \mathrm{C}\right)$, observed number of alleles $\left(N_{\mathrm{A}}\right)$, expected heterozygosity $\left(H_{\mathrm{E}}\right)$, Polymorphic Information Content $(P I C)$, null allele frequencies $(r)$ and private alleles across 10 Taiwan commercial native chicken populations, two exotic breeds and one red jungle fowl population

\begin{tabular}{ccccrcccl}
\hline \hline Locus & GGA & Allele range & $T_{\mathrm{A}}$ & $N_{\mathrm{A}}$ & $H_{\mathrm{E}}$ & $P I C^{1}$ & $r($ Null $)$ & \\
\hline ADL0112 & 10 & $122-130$ & 59 & 5 & 0.619 & 0.564 & 0.022 & \multicolumn{1}{c}{ Private alleles $^{2}$} \\
ADL0268 & 1 & $102-114$ & 60 & 6 & 0.774 & 0.736 & 0.060 & \\
ADL0278 & 8 & $99-123$ & 59 & 9 & 0.680 & 0.622 & 0.056 & $99(0.02) ; 109(0.04)$ \\
LEI0192 & 6 & $234-332$ & 60 & 25 & 0.688 & 0.665 & 0.109 & $236(0.01) ; 262(0.01) ; 268(0.07) ; 286(0.02) ; 304(0.02) ;$ \\
& & & & & & & & $314(0.02) ; 332(0.02)$ \\
MCW0014 & 6 & $165-189$ & 60 & 10 & 0.583 & 0.513 & 0.109 & $166(0.32) ; 171(0.45) ; 183(0.06) ; 187(0.02)$ \\
MCW0034 & 2 & $215-245$ & 59 & 14 & 0.597 & 0.574 & 0.128 & $215(0.11) ; 219(0.23) ; 221(0.09) ; 241(0.02) ; 243(0.04)$ \\
MCW0037 & 3 & $152-158$ & 62 & 4 & 0.576 & 0.524 & 0.024 & \\
MCW0067 & 10 & $174-186$ & 60 & 7 & 0.642 & 0.578 & 0.037 & $174(0.09) ; 176(0.02) ; 186(0.18)$ \\
MCW0069 & 26 & $155-177$ & 60 & 12 & 0.752 & 0.716 & 0.059 & $162(0.04)$ \\
MCW0078 & 8 & $136-144$ & 60 & 5 & 0.550 & 0.508 & 0.064 & \\
MCW0081 & 5 & $107-133$ & 60 & 7 & 0.636 & 0.565 & 0.101 & $107(0.02) ; 132(0.01)$ \\
MCW0098 & 4 & $255-265$ & 60 & 4 & 0.498 & 0.379 & 0.014 & $265(0.03)$ \\
MCW0103 & 3 & $264-276$ & 62 & 6 & 0.397 & 0.351 & 0.086 & $272(0.07) ; 276(0.02)$ \\
MCW0111 & 1 & $96-106$ & 60 & 6 & 0.620 & 0.556 & 0.036 & $96(0.05)$ \\
MCW0183 & 7 & $292-319$ & 60 & 11 & 0.764 & 0.730 & 0.080 & $307(0.02) ; 309(0.09) ; 317(0.10) ; 319(0.10)$ \\
MCW0206 & 2 & $221-241$ & 60 & 8 & 0.750 & 0.712 & 0.029 & $231(0.70) ; 241(0.39)$ \\
MCW0216 & 13 & $136-150$ & 60 & 7 & 0.598 & 0.521 & 0.067 & $140(0.11)$ \\
MCW0222 & 3 & $219-225$ & 60 & 4 & 0.556 & 0.511 & 0.030 & \\
MCW0248 & 1 & $216-224$ & 59 & 4 & 0.411 & 0.378 & 0.023 & $218(0.32)$ \\
MCW0284 & 4 & $234-242$ & 58 & 5 & 0.508 & 0.419 & 0.028 & $236(0.07)$ \\
MCW0295 & 4 & $81-99$ & 60 & 9 & 0.764 & 0.725 & 0.085 & $81(0.08)$ \\
MCW0330 & 17 & $246-286$ & 60 & 8 & 0.797 & 0.768 & 0.121 & $246(0.43)$ \\
\hline Mean & & & & 8.0 & 0.625 & 0.573 & 0.069 & \\
\hline
\end{tabular}

${ }^{1}$ PIC $>0.50$ indicating a high level of polymorphism, $0.25<P I C<0.50$ indicating a medium level of polymorphism and $P I C<0.25$ indicating a low level of polymorphism;

${ }^{2}$ Values in brackets indicated the frequency (\%) of private alleles.

to estimate the highest similarity coefficient (Rosenberg et al., 2001) over all runs for different value of $K$ using LARGKGREEDY algorithm to compute the similarity function $G^{\prime}$. The $Q$ matrix with the highest similarity was used for graphical representation of individual assignments by DISTRUCT 1.1 program (Rosenberg, 2004). The second step applied the method suggested by Rosenberg et al. (2001) for the evaluation of individual breed assignment. At $K=2$, Game bird was differentiated from other 12 populations so we ran structure on the 12 remaining populations using $K=1$ to 15 as number of genetic clusters following the procedures in the first step. The third step, we analyzed separately the subcluster involving four breeds (i.e., Classical chicken, Black feathered, Red feathered and Golden chicken) from $K=1$ to 6 and the last subcluster involving two breeds (i.e., Hakka strain and Naked Neck) from $K=1$ to 5 as the procedures in the first step to quantify the admixture pattern.

\section{Results and Discussion}

\section{Polymorphism of Microsatellite Markers}

The null allele frequency of all 22 markers was lower than 0.20 (Table 1) so we assumed that null alleles were absent (Chapuis and Estoup, 2007). As a result, these 22 markers were used for further analyzes. Among 22 microsatellite markers, a total of 176 alleles were detected across 13 populations. The mean number of alleles per locus was 8 and ranged from 4 to 25 . The expected heterozygosity per locus averaged 0.625 and varied from 0.397 for locus MCW0103 to 0.797 for locus MCW0330. On average, the PIC value was 0.573 suggested that those 22 markers showed polymorphism in 10 TCOM populations, two exotic breeds and the red jungle fowl population (Botstein, 1980).

\section{Genetic Diversity within Chicken Breeds}

Within 10 TCOM populations, the average number of alleles per breed was 4.0 and ranged from 3.2 for Game bird to 4.8 for Black feathered chickens (Table 2). The number of alleles was similar to that of red jungle fowl population (3.8, Table 2) but higher than that of two exotic breeds (2.9 in White Leghorn and 3.2 in White broiler, respectively) in this study. The mean effective number of alleles was 2.4 , the lowest value (2.0) was found in B and L2 strains while the highest value was 2.7 in Classical chicken. This averaged value was equal to the one found in red jungle fowl population (2.4) but lower compared to the value of 3.7 found in Indian chickens using 9 microsatellite markers (Pirany et al., 2007). Among 13 populations, two populations, Hakka chicken and White broiler had no private alleles. The observed number of private alleles averaged 2.6 for overall 
Table 2. Number of samples $(n)$, observed number of alleles $\left(N_{\mathrm{A}}\right)$, effective number of alleles $\left(N_{\mathrm{E}}\right)$, number of private alleles $\left(N_{\mathrm{P}}\right)$, allelic richness $(A R)$, observed $\left(H_{\mathrm{O}}\right)$ and expected $\left(H_{\mathrm{E}}\right)$ heterozygosity, Polymorphic Information Content $(P I C)$, inbreeding coefficient $\left(F_{I S}\right)$ and number of loci deviating from Hardy-Weinberg equilibrium test $(\mathrm{dHWE})$ within 10 Taiwan commercial native populations, two exotic breeds and one red jungle fowl population based on 22 microsatellites

\begin{tabular}{lcccccccccc}
\hline \hline \multicolumn{1}{c}{ Population } & $n$ & $N_{\mathrm{A}}$ & $N_{\mathrm{E}}$ & $N_{\mathrm{P}}$ & $A R$ & $H_{\mathrm{O}}$ & $H_{\mathrm{E}}$ & $P I C^{1}$ & $F_{\mathrm{IS}}$ & $d H W E$ \\
\hline Red jungle fowl (JF) & 22 & 3.8 & 2.4 & 10 & 3.4 & 0.419 & 0.536 & 0.468 & 0.223 & 3 \\
White broiler (BR) & 24 & 3.2 & 2.2 & 0 & 2.9 & 0.541 & 0.502 & 0.433 & -0.057 & 0 \\
White Leghorn (LG) & 54 & 2.9 & 2.1 & 3 & 2.6 & 0.476 & 0.429 & 0.377 & -0.129 & 1 \\
\hline
\end{tabular}

\begin{tabular}{lllllllllll}
\multicolumn{1}{l}{ Taiwan commercial native chickens (TCOM): } \\
\hline B strain (BS) & 45 & 3.3 & 2.0 & 1 & 2.7 & 0.363 & 0.444 & 0.381 & 0.220 & 4 \\
L2 strain (LS) & 51 & 3.6 & 2.0 & 3 & 2.8 & 0.322 & 0.419 & 0.372 & 0.218 & 4 \\
Hakka strain (HS) & 27 & 3.6 & 2.3 & 1 & 3.0 & 0.473 & 0.521 & 0.442 & 0.090 & 0 \\
Black feathered (BF) & 46 & 4.8 & 2.6 & 3 & 3.6 & 0.502 & 0.582 & 0.522 & 0.145 & 3 \\
Classical chicken (CC) & 26 & 4.5 & 2.7 & 3 & 3.8 & 0.481 & 0.592 & 0.522 & 0.169 & 2 \\
Game bird (GB) & 42 & 3.2 & 2.2 & 4 & 2.8 & 0.435 & 0.485 & 0.415 & 0.108 & 0 \\
Golden chicken (GC) & 13 & 3.8 & 2.6 & 1 & 3.6 & 0.430 & 0.607 & 0.522 & 0.283 & 3 \\
Hakka chicken (HC) & 45 & 4.0 & 2.5 & 0 & 3.3 & 0.506 & 0.578 & 0.509 & 0.125 & 2 \\
Naked Neck (NN) & 49 & 4.7 & 2.5 & 6 & 3.5 & 0.457 & 0.547 & 0.488 & 0.166 & 3 \\
Red feathered (RF) & 49 & 4.5 & 2.4 & 4 & 3.4 & 0.419 & 0.532 & 0.475 & 0.217 & 7 \\
\hline \multicolumn{1}{c}{ Mean of TCOM } & & 4.0 & 2.4 & 2.6 & 3.3 & 0.439 & 0.531 & 0.465 & 0.174 & 2.8 \\
\hline
\end{tabular}

${ }^{1}$ The $P I C>0.50$ indicating a high level of polymorphism, $0.25<$ PIC $<0.50$ indicating a medium level of polymorphism and $P I C<$ 0.25 indicating a low level of polymorphism.

10 TCOM populations. This value is lower than 10 alleles in red jungle fowl (Table 1) and 9.8 alleles in Indian chickens (Pirany et al., 2007). Allelic richness, based on minimum sample size of nine diploid individuals, averaged 3.3 which varied from 2.7 in B strain to 3.8 in Classical chicken, respectively. This mean value is lower than in red jungle fowl (3.4) but higher than that of two exotic breeds (2.6 in White Leghorn and 2.9 in White broiler, respectively), but also higher compare to Vietnamese local chickens (2.9, Berthouly et al., 2009). The average values of the observed and expected heterozygosity harbored 0.439 and 0.531 , respectively, which are very similar to the values of 0.419 and 0.536 in red jungle fowl as well as the value of 0.488 found in six Taiwan conserved chicken breeds using 22 loci (Berthouly et al., 2008), but higher than the values ranging from 0.296 to 0.344 and from 0.341 to 0.395 found in four Nagoya strains, respectively (Takahashi and Nakamura, 2007). This can be partly explained as Nagoya strains were established in 1919 and have been selected for meat and egg since then. In contrast, TCOM populations have been managed in a way that enhances gene flow between flocks, and they have combined gene pools from different breeds (Lee, 2006; Tadano et al., 2007) and thus increase their genetic diversity. For example, Hakka people prefer to keep their native chickens but they do not reproduce their own chicks, they always purchase large and sturdy chicks from hatchery or salesman irrespective to a specific breed (Lee, 2006). Such results are also consistent with values observed in village chickens in both Zimbabwe (Muchadeyi et al., 2007) and Ethiopia (Goraga et al., 2012) where local chickens have not been selected for performance traits and are managed in a free-range system. The $F_{\text {IS }}$ values ranged from 0.090 in Hakka strain to 0.283 in Golden chicken, which is a much larger range than the range observed in Taiwanese conserved chicken breeds ( -0.053 to 0.068$)$ by Berthouly et al. (2008). The present values of $F_{\text {IS }}$ indicate a high inbreeding in Golden chicken, red jungle fowl and the remaining nine TCOM populations but an excess of heterozygotes in White Leghorn and White broiler populations. On average, 2.8 $(0-7)$ of 22 loci deviated significantly from HWE suggesting a slight loss of heterozygosity. The high inbreeding rates reflect the fact that TCOM populations were developed from a small number of chicken and/or a strong selection for production efficiency and meat quality.

\section{Breed Relationship and Population Clustering}

The NJ tree based on $D_{\mathrm{R}}$ pairwise genetic distance presented a poor resolution with only two branches showing bootstrap values above $70 \%$. Hakka and L2 strains were closed to Naked Neck with bootstrap values of $76.4 \%$, and then clustering with White broiler with $100 \%$ bootstraps (Fig. 2). Hakka strain is a crossbreed between Hakka chicken and L2 strain. This strain seemed to be closer to L2 strain than Hakka chicken, which would indicate a higher contribution of L2 strain than Hakka chicken into Hakka strain. However, the $D_{\mathrm{A}}$ and $D_{\mathrm{R}}$ genetic distances amongst these three breeds were quite similar. The $D_{\mathrm{A}}$ genetic distances between Hakka strain and Hakka chicken, and Hakka and L2 strains were 0.165 and 0.150 , respectively, while $D_{\mathrm{R}}$ genetic distances between Hakka strain and Hakka chicken, and Hakka and L2 strains were 0.161 and 0.189 , respectively. L2 and $\mathrm{B}$ strains originate from the same original population while the $D_{\mathrm{A}}$ genetic distance between L2 and B strains was 


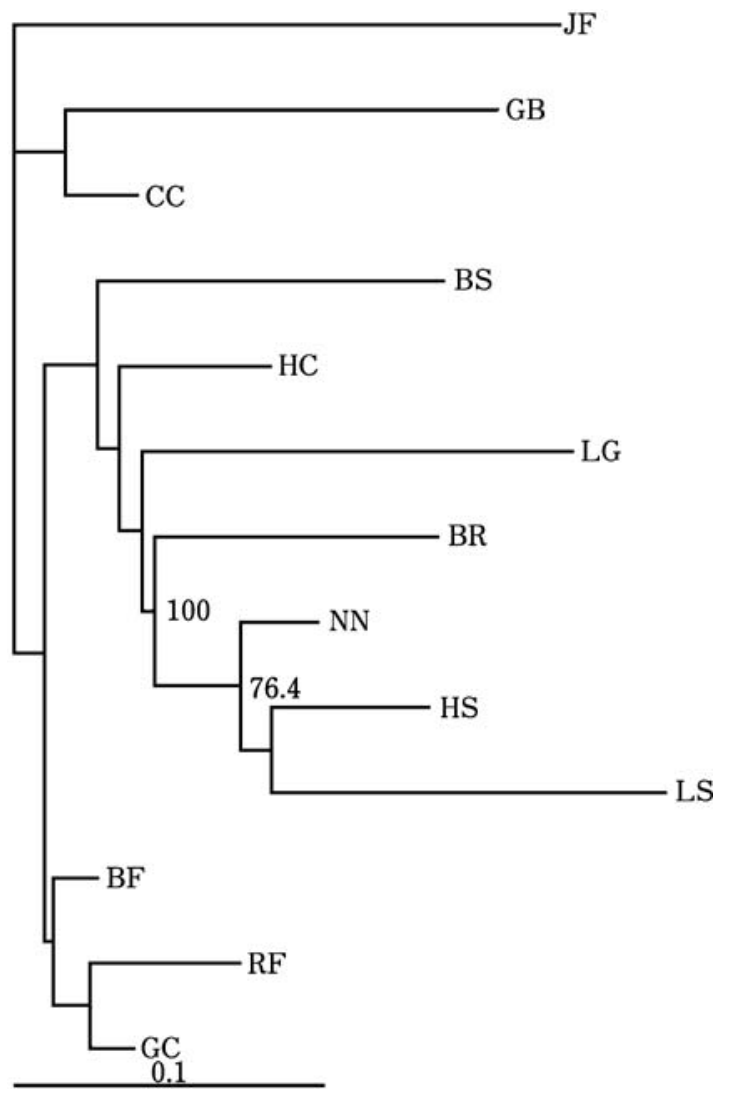

Fig. 2. Neighbor-joining tree of $\mathbf{1 0}$ Taiwan commercial native chicken populations, two exotic breeds and one red jungle fowl population based on $D_{\mathrm{R}}$ genetic distance. Bootstrap values $\geq 70$ were presented. The abbreviation of chickens is: red jungle fowl (JF); White Leghorn (LG); White broiler (BR); 10 Taiwan commercial native chickens: Game bird (GB), Classical chicken (CC), B strain (BS), Hakka chicken (HC), Naked Neck (NN), Hakka strain (HS) and L2 strain (LS), Black feathered (BF), Red feathered (RF) and Golden chicken (GC).

0.189 (Table 3). This genetic distance is higher than the one found between two Nagoya strains $(0.140$; Takahashi and Nakamura, 2007). Despite this common origin, they did not cluster in a significant way in the tree. A possible explanation to this is a strong effect of different selection objectives: meat vs. egg production lead to a clear genetic divergence between subpopulations (Takahashi and Nakamura, 2007). Moreover, small population size and therefore high inbreeding rates contribute to genetically differentiate subpopulations having the same origin (Frankham, 1996; Allendorf et al., 2010).

Table 4 represented the analysis of global AMOVA for 12 Taiwan domestic chicken populations. When 10 TCOM populations were considered separately and grouped as TCOM vs. CEB (commercial exotic breeds), a non-significant genetic variation was obtained among groups (only 5.8
$\%, P>0.05)$ indicated a very low genetic variation among two groups. Within groups, either TCOM or CEB, the highest genetic variation was found within populations $(>75$ $\%)$. Overall, this indicates a small genetic variation between populations within and among groups and it is therefore in agreement with the poor resolution that we found with the NJ tree.

The well-known Bayesian clustering approach (Pritchard et al., 2000) detects the population structure based on the proposition of admixture between genetically divergent populations without a priori information of breeds (Allendorf et al., 2010; Tadano et al., 2011) and differs from traditional methods such as phylogenetic trees which assume genetic separation between breeds (Granevitze et al., 2009; Tixier-Boichard et al., 2009). The highest $\Delta K$ value was found at $K=2$ (data not shown) according to Evanno et al. (2005). At $K=2$, Game bird was the most distinguished from other populations (Fig. 3A). Using Rosenberg et al. (2001) approach, the highest $\Delta K$ values for the remaining 12 populations were at $K=3, K=7$ and $K=12$. Leroy et al. (2009) suggested that the highest values for small number of $K$ are biased with Evanno method as the number of breeds was crucial in the dataset. At $K=3$, only White Leghorn could be distinguished from the remaining populations. With regard to $K=7$, Hakka strain, Naked Neck and White broiler were clustered together. For $K=12$, the male-line B strain, the female-line L2 strain, White broiler and White Leghorn were clearly assigned to their own cluster with average proportion of membership higher than 0.90 (Table 5) where a few individuals exhibited a larger degree of admixture (Fig. 3B). Red jungle fowl, Hakka chicken and Hakka strain could be assigned to their own cluster (Figs 3B and 3D) with proportion of membership higher than 0.85 suggesting more recent admixed ancestry as found in Swiss goats (Glowatzki-Mullis et al., 2008). Naked Neck population surprisingly shared more than a third of its genetic pool with Hakka strain. These results are similar to those found in the NJ tree. The four admixed populations (i.e., Red feathered, Black feathered, Golden chicken and Classical chicken), when analyzed apart, still could not be distinguished with the low proportion of membership (Fig. 3C). As their known breeding history, they were genetically related together. Similarly, a substructure was found in Naked Neck chicken (Fig. 3D), this chicken breed had a complex genetic background and individuals were assigned to diverse clusters. Muchadeyi et al. (2007) also reported that Zimbabwe chicken population was absent of substructuring among five ecotypes due to extensive gene flow among populations. Furthermore, breeds with high-within-breed diversity $\left(H_{\mathrm{E}}\right)$ revealed a low assignation by using Bayesian cluster approach as suggested by Leroy et al. (2009).

The population structure results showed that Taiwan commercial native chickens are more admixed, in contrast to occidental highly productive breeds. The high genetic variation within breed as shown in AMOVA results, facilitated by gene exchanges, did not allow discriminating in an efficient way for all the populations. The results suggest that the 
Table 3. The $D_{\mathrm{A}}$ genetic distance below the diagonal and $D_{\mathrm{R}}$ above the diagonal between pairs of 10 Taiwan commercial native chicken populations, two exotic breeds and one red jungle fowl population

\begin{tabular}{lccccccccccccc}
\hline \hline Populations $^{1}$ & JF & GB & CC & RF & GC & HS & HC & BF & BS & LS & LG & BR & NN \\
\hline JF & - & 0.350 & 0.259 & 0.270 & 0.207 & 0.331 & 0.283 & 0.207 & 0.382 & 0.471 & 0.447 & 0.347 & 0.307 \\
GB & 0.374 & - & 0.166 & 0.267 & 0.208 & 0.348 & 0.257 & 0.193 & 0.351 & 0.525 & 0.361 & 0.389 & 0.272 \\
CC & 0.324 & 0.194 & - & 0.112 & 0.065 & 0.150 & 0.124 & 0.042 & 0.157 & 0.292 & 0.250 & 0.188 & 0.122 \\
RF & 0.306 & 0.227 & 0.112 & - & 0.043 & 0.164 & 0.143 & 0.059 & 0.206 & 0.281 & 0.279 & 0.170 & 0.145 \\
GC & 0.297 & 0.216 & 0.098 & 0.072 & - & 0.137 & 0.063 & 0.026 & 0.158 & 0.284 & 0.209 & 0.124 & 0.117 \\
HS & 0.357 & 0.306 & 0.163 & 0.158 & 0.168 & - & 0.161 & 0.140 & 0.270 & 0.189 & 0.283 & 0.153 & 0.087 \\
HC & 0.351 & 0.252 & 0.140 & 0.154 & 0.120 & 0.165 & - & 0.089 & 0.175 & 0.252 & 0.213 & 0.137 & 0.112 \\
BF & 0.278 & 0.202 & 0.071 & 0.072 & 0.073 & 0.154 & 0.121 & - & 0.147 & 0.247 & 0.212 & 0.144 & 0.110 \\
BS & 0.351 & 0.294 & 0.164 & 0.175 & 0.142 & 0.231 & 0.165 & 0.150 & - & 0.269 & 0.287 & 0.270 & 0.186 \\
LS & 0.398 & 0.423 & 0.237 & 0.214 & 0.225 & 0.150 & 0.211 & 0.211 & 0.189 & - & 0.387 & 0.284 & 0.155 \\
LG & 0.422 & 0.316 & 0.255 & 0.270 & 0.217 & 0.269 & 0.234 & 0.234 & 0.220 & 0.310 & - & 0.251 & 0.202 \\
BR & 0.370 & 0.346 & 0.173 & 0.149 & 0.140 & 0.149 & 0.146 & 0.150 & 0.190 & 0.237 & 0.236 & - & 0.153 \\
NN & 0.318 & 0.247 & 0.121 & 0.128 & 0.131 & 0.093 & 0.110 & 0.100 & 0.167 & 0.160 & 0.201 & 0.123 & - \\
\hline
\end{tabular}

${ }^{1}$ Red jungle fowl (JF), Game bird (GB), Classical chicken (CC), Red feathered (RF), Golden chicken (GC), Hakka strain (HS), Hakka chicken (HC), Black feathered (BF), B strain (BS), L2 strain (LS), White Leghorn (LG), White broiler (BR) and Naked Neck (NN).

Table 4. AMOVA partitions of $\mathbf{1 0}$ Taiwan commercial native chicken populations and two exotic breeds based on 22 microsatellite markers

\begin{tabular}{lccc}
\hline \hline \multirow{2}{*}{ Groups } & \multicolumn{3}{c}{ Source of variation (\%) } \\
\cline { 2 - 4 } & Among groups & $\begin{array}{c}\text { Among populations } \\
\text { within groups }\end{array}$ & Within populations \\
\hline All 12 breeds - in one group & $20.24(0.000)$ & $79.76(0.000)$ \\
Ten TCOM ${ }^{1}-$ in one group & & $19.37(0.000)$ & $80.63(0.000)$ \\
CEB $^{2}-$ in one group & $5.83(0.058)$ & $17.64(0.000)$ & $75.32(0.000)$ \\
TCOM vs. CEB & $56.53(0.000)$ \\
\hline
\end{tabular}

${ }^{1}$ Ten Taiwan commercial native chickens were consisted of B strain (BS), L2 strain (LS), Hakka strain (HS), Hakka chicken (HC), Black feathered (BF), Red feathered (RF), Golden chicken (GC), Classical chicken (CC), Game bird (GB) and Naked Neck (NN).

${ }^{2}$ Commercial exotic breeds were consisted of White broiler (BR) and White Leghorn (LG). The significance tests were computed based on 1,023 permutations; $P$ values (Probability level) were given in parentheses.

genetic pool of Taiwan commercial native chickens is well distributed among breeds and therefore there is a good potential for adaptation to new environmental conditions or markets. Therefore, management needs to be taken into account for the populations, especially B strain, Golden chicken and L2 strain with $F_{\text {IS }}$ values above 0.20 , to prevent inbreeding depression and maximize genetic diversity as suggested by Eding et al. (2002) and Toro et al. (2009) methods.

\section{Acknowledgments}

The authors would like to thank National Science Council, Taiwan for its financial supports (Project number NSC-3111Y-466-005). The first author would gratefully thank for support from Taiwan Scholarship Program. We would like to thank two anonymous reviewers for useful comments. 
A
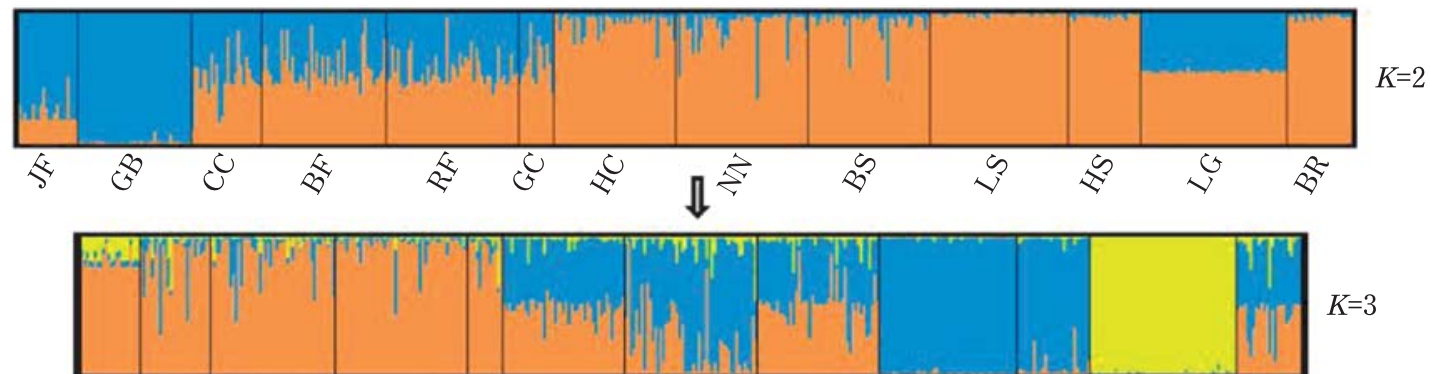

B
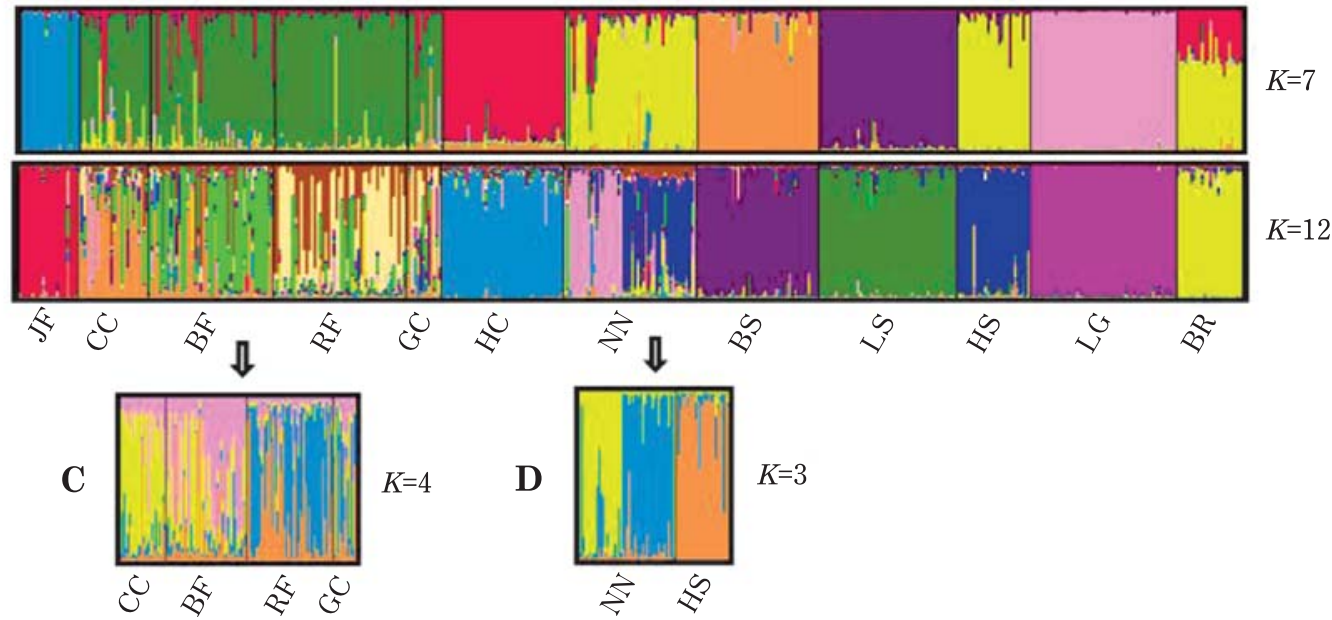

Fig. 3. Genetic structure of $\mathbf{1 0}$ Taiwan commercial native chicken populations, two exotic breeds and one red jungle fowl population. A: Clustering diagrams of 10 Taiwan commercial native chicken populations, two exotic breeds and red jungle fowl population obtained from $K=2$, using $Q$ matrices over 50 runs with the highest similarities. B: Clustering diagrams of nine Taiwan commercial native chicken populations (i.e., after removing Game bird population), two exotic breeds and red jungle fowl population obtained from $K=3, K=7$ and $K=12$. C: Clustering diagrams of four populations (i.e., Classical chicken, Black feathered, Red feathered and Golden chicken) were at $K=4$. D: Clustering diagrams of two populations (i.e., Naked Neck and Hakka strain) at $K=3$. The black lines separate individuals of different populations: red jungle fowl (JF), Game bird (GB), Classical chicken (CC), Black feathered (BF), Red feathered (RF), Golden chicken (GC), Hakka chicken (HC), Naked Neck (NN), B strain (BS), L2 strain (LS), Hakka strain (HS), White Leghorn (LG) and White broiler (BR).

Table 5. The proportion of membership of each of the nine Taiwan commercial native chicken populations, two exotic breeds and one red jungle fowl population (after removing Game bird population) in the 12 inferred clusters using STRUCTURE analysis

\begin{tabular}{|c|c|c|c|c|c|c|c|c|c|c|c|c|c|}
\hline \multirow[t]{2}{*}{ Populations $^{1}$} & \multicolumn{13}{|c|}{ Inferred clusters ${ }^{2}$} \\
\hline & 1 & 2 & 3 & 4 & 5 & 6 & 7 & 8 & 9 & 10 & 11 & 12 & $n$ \\
\hline $\mathrm{JF}$ & 0.019 & 0.008 & 0.006 & 0.007 & 0.006 & 0.006 & 0.895 & 0.015 & 0.005 & 0.003 & 0.015 & 0.015 & 22 \\
\hline $\mathrm{CC}$ & 0.556 & 0.018 & 0.013 & 0.080 & 0.016 & 0.037 & 0.005 & 0.103 & 0.031 & 0.014 & 0.052 & 0.075 & 26 \\
\hline $\mathrm{BF}$ & 0.185 & 0.036 & 0.023 & 0.024 & 0.015 & 0.019 & 0.008 & 0.482 & 0.023 & 0.013 & 0.042 & 0.130 & 46 \\
\hline $\mathrm{RF}$ & 0.015 & 0.013 & 0.035 & 0.015 & 0.011 & 0.013 & 0.005 & 0.110 & 0.013 & 0.008 & 0.474 & 0.288 & 49 \\
\hline GC & 0.193 & 0.059 & 0.033 & 0.009 & 0.010 & 0.088 & 0.010 & 0.097 & 0.010 & 0.044 & 0.296 & 0.150 & 13 \\
\hline $\mathrm{NN}$ & 0.028 & 0.028 & 0.046 & 0.402 & 0.023 & 0.023 & 0.011 & 0.036 & 0.321 & 0.018 & 0.011 & 0.053 & 49 \\
\hline $\mathrm{HC}$ & 0.012 & 0.868 & 0.013 & 0.024 & 0.016 & 0.011 & 0.003 & 0.011 & 0.009 & 0.010 & 0.008 & 0.013 & 45 \\
\hline BS & 0.006 & 0.008 & 0.011 & 0.012 & 0.013 & 0.901 & 0.006 & 0.007 & 0.010 & 0.011 & 0.010 & 0.006 & 45 \\
\hline LS & 0.005 & 0.005 & 0.005 & 0.008 & 0.924 & 0.010 & 0.004 & 0.010 & 0.014 & 0.004 & 0.005 & 0.006 & 51 \\
\hline HS & 0.016 & 0.008 & 0.039 & 0.017 & 0.021 & 0.006 & 0.003 & 0.007 & 0.858 & 0.005 & 0.009 & 0.011 & 27 \\
\hline LG & 0.003 & 0.003 & 0.003 & 0.005 & 0.004 & 0.005 & 0.002 & 0.003 & 0.004 & 0.962 & 0.003 & 0.003 & 54 \\
\hline BR & 0.006 & 0.008 & 0.905 & 0.009 & 0.009 & 0.007 & 0.003 & 0.008 & 0.013 & 0.012 & 0.013 & 0.008 & 24 \\
\hline
\end{tabular}

${ }^{1}$ Red jungle fowl (JF), Classical chicken (CC), Black feathered (BF), Red feathered (RF), Golden chicken (GC), Hakka chicken (HC), Naked Neck (NN), B strain (BS), L2 strain (LS), Hakka strain (HS), White Leghorn (LG) and White broiler (BR).

${ }^{2}$ The contribution higher than 0.80 are in bold; $n$ : Number of samples. 


\section{References}

Allendorf FW, Hohenlohe PA and Luikart G. Genomics and the future of conservation genetics. Nature Reviews Genetics, 11: 697-709. 2010.

Berthouly C, Bed'Hom B, Tixier-Boichard M, Chen CF, Lee YP, Laloë D, Legros H, Verrier E and Rognon X. Using molecular markers and multivariate methods to study the genetic diversity of local European and Asian chicken breeds. Animal Genetics, 39: 121-129. 2008.

Berthouly C, Leroy G, Nhu VT, Hoang TH, Bed'Hom B, Nguyen TB, Vu CC, Monicat F, Tixier-Boichard M, Verrier E, Maillard $\mathrm{J}-\mathrm{C}$ and Rognon X. Genetic analysis of local Vietnamese chickens provides evidence of gene flow from wild to domestic populations. BMC Genetics, 10: 1. 2009.

Boettcher PJ, Tixier-Boichard M, Toro MA, Simianer H, Eding H, Gandini G, Joost S, Garcia D, Colli L, Ajmone-Marsan P and the GC. Objectives, criteria and methods for using molecular genetic data in priority setting for conservation of animal genetic resources. Animal Genetics, 41: 64-77. 2010.

Botstein D, White RL, Skolnick M and Davis RW. Construction of a genetic linkage map in man using restriction fragment polymorphisms. American Journal of Human Genetics, 32: 314331. 1980.

Chang CS, Chen CF, Berthouly-Salazar C, Chazara O, Lee YP, Chang CM, Chang KH, Bed'Hom B and Tixier-Boichard M. A global analysis of molecular markers and phenotypic traits in local chicken breeds in Taiwan. Animal Genetics, 43: 172182. 2012

Chao $\mathrm{CH}$ and Lee YP. Relationship between reproductive performance and immunity in Taiwan country chickens. Poultry Science, 80: 535-540. 2001.

Chapuis MP and Estoup A. Microsatellite null alleles and estimation of population differentiation. Molecular Biology and Evolution, 24: 621-631. 2007.

Chen CF, Berthouly C, Rognon X, Chang KH, Laloë D, Legros H, Verrier E, Tixier-Boichard M and Lee YP. Characterization of six Asian local chicken breeds: performances and polymorphism from microsatellite markers. The $29^{\text {th }}$ International Conference on International Society of Animal Genetics (ISAG), Tokyo, Japan. 2004.

Chen CF, Lee YP, Tixier-Boichard M, Bed'hom B, Chang CM and Coville JL. Single nucleotide polymorphism in the melanocortin-1 receptor gene of local chickens. Journal of the Chinese Society of Animal Science, 34 (suppl.): 99. 2005.

Chen CF, Shiue YL, Yen CJ, Tang PC and Lee YP. Laying traits and underlying transcripts, expressed in the hypothalamus and pituitary gland that were associated with egg production variability in chickens. Theriogenology, 68: 1305-1313. 2007.

Dalvit C, De Marchi M and Cassandro M. Genetic traceability of livestock products: a review. Meat Science, 77: 437-449. 2007.

Dent EA and Bridgett MVH. STRUCTURE HARVESYER: a website and program for visualizing STRUCTURE output and implementing the Evanno method. Conservation Genetics Resources, 4: 359-361. 2012.

Eding H, Crooijmans RPMA, Groenen MA and Meuwissen TH. Assessing the contribution of breeds to genetic diversity in conservation schemes. Genetics, Selection, Evolution, 34: 613-633. 2002.

Evanno G, Regnaut S and Goudet J. Detecting the number of clusters of individuals using the software Structure: a simu- lation study. Molecular Ecology, 14: 2611-2620. 2005.

Excoffier L and Lischer HEL. Arlequin suite version 3.5: a new series of programs to perform population genetics analyzes under Linux and Windows. Molecular Ecology Resources, 10: 564-567. 2010.

Falush D, Stephens M and Pritchard JK. Inference of population structure using multilocus genotype data: linked loci and correlated allele frequencies. Genetics, 164: 1567-1587. 2003.

Felsenstein J. Phylip (Phylogeny Inference Package) version 3.69. Department of Genome Sciences, University of Washington, Seattle. 2009.

Frankham R. Relationship of genetic variation to population size in wildlife. Conservation Biology, 10: 1500-1508. 1996.

Glowatzki-Mullis ML, Muntwyler J, Bäumle E and Gaillard C. Genetic diversity measures of Swiss goat breeds as decisionmaking support for conservation policy. Small Ruminant Research, 74: 202-211. 2008.

Gorage Z, Weigend S and Brockmann G. Genetic diversity and population structure of five Ethiopian chicken ecotypes. Animal Genetics, 43: 454-457. 2012.

Goudet J. FSTAT: a program to estimate and test gene diversities and fixation indices, version 2.9.3. Department of Ecology and Evolution, Lausanne University, CH-1015, Switzerland. 2002.

Granevitze Z, Hillel J, Feldman M, Six A, Eding H and Weigend S. Genetic structure of a wide-spectrum chicken gene pool. Animal Genetics, 40: 686-693. 2009.

Guo SW and Thompson EA. Performing the exact test of HardyWeinberg proportion for multiple alleles. Biometrics, 48: 361-372. 1992 .

Hillel J, Groenen MAM, Tixier-Boichard M, Korol AB, David L, Kirzhner VM, Burke T, Barre-Dirie A, Crooijmans RP, Elo K, Feldman MW, Freidlin PJ, Mäki-Tanila A, Oortwijn M, Thomson P, Vignal A, Wimmers K and Weigend S. Biodiversity of 52 chicken populations assessed by microsatellite typing of DNA pools. Genetics, Selection, Evolution, 35: 533-557. 2003.

Jakobsson $\mathrm{M}$ and Rosenberg N. Clumpp: a cluster matching and permutation program for dealing with label switching and multimodality in analysis of population structure. Bioinformatics, 23: 1801-1806. 2007.

Kalinowski ST, Taper ML and Marshall TC. Revising how the computer program Cervus accommodates genotyping error increases success in paternity assignment. Molecular Ecology, 16: 1099-1106. 2007.

Kumar S, Skjaeveland A, Orr R, Enger P, Ruden T, Mevik BH, Burki F, Botnen A and Shalchian-Tabrizi K. AIR: a batchoriented web program package for construction of supermatrices ready for phylogenomic analyzes. BMC Bioinformatics, 10: 357. 2009.

Langella O. Populations 1.2.32, CNRS UPR9034, France. 1999.

Lee YP. Taiwan country chicken: a slow growth breed for eating quality. In: Symposium 7-10 November, Scientific Cooperation in Agriculture between Council of Agriculture (Taiwan, R.O.C.) and Institut National de Recherche Agronomique, France (Liao CW, Shih BL, Lee ML, Hsu AL and Cheng YS eds.). Technical Bulletin of Livestock Research Institute, 103: 121-132. 2006.

Leroy G, Verrier E, Meriaux JC and Rognon X. Genetic diversity of dog breeds: between-breed diversity, breed assignation and conservation approaches. Animal Genetics, 40: 333-343. 2009.

Miller SA, Dykes DD and Polesky HF. A simple salting out procedure for extracting DNA from human nucleated cells. 
Nucleic Acids Research, 16: 1215. 1988.

Muchadeyi FC, Eding H, Wollny CBA, Groeneveld E, Makuza SM, Shamseldin R, Simianer $\mathrm{H}$ and Weigend S. Absence of population substructuring in Zimbabwe chicken ecotypes inferred using microsatellite analysis. Animal Genetics, 38: 332-339. 2007.

Nakamura A, Nagao K, Watanabe H and Kondo H. Characteristics of PCR fragments amplified using five microsatellite markers for identifying the Nagoya breed. Animal Science Journal, 81: 438-443. 2010.

Nei M, Tajima F and Tateno Y. Accuracy of estimated phylogenetic trees from molecular data. Journal of Molecular Evolution, 19: 153-170. 1983.

Nishibori M, Shimogiri T, Hayashi T and Yasue H. Molecular evidence for hybridization of species in the genus Gallus except for Gallus varius. Animal Genetics, 36: 367-375. 2005.

Nishida T, Rerkamnuaychoke W, Tung DG, Saignaleus S, Okamoto S, Kawamoto Y, Kimura J, Kawabe K, Tsunekawa N, Otaka H and Hayashi Y. Morphological identification and ecology of the red jungle fowl in Thailand, Laos and Vietnam. Animal Science Journal, 71: 470-480. 2000.

Peakall R and Smouse PE. Genalex 6: genetic analysis in Excel. Population genetic software for teaching and research. Molecular Ecology Notes, 6: 288-295. 2006.

Pirany N, Romanov MN Ganpule SP, Devegowda G and Prasad DT. Microsatellite analysis of genetic diversity in Indian chicken populations. Journal of Poultry Science, 44: 19-28. 2007.

Pritchard JK, Stephens M and Donnelly P. Inference of population structure using multilocus genotype data. Genetics, 155: 945959. 2000.

Reynolds J, Weir BS and Cockerham CC. Estimation of the coancestry coefficient: basis for a short-term genetic distance. Genetics, 105: 767-779. 1983.

Rosenberg NA, Burke T, Elo K, Feldman MW, Friedlin PJ, Groenen MAM, Hillel J, Mäki-Tanila A, Tixier-Boichard M, Vignal A,
Wimmers $\mathrm{K}$ and Weigend S. Empirical evaluation of genetic clustering methods using multilocus genotypes from 20 chicken breeds. Genetics, 159: 699-713. 2001.

Rosenberg NA. Distruct: a program for the graphical display of population structure. Molecular Ecology Notes, 4: 137-138. 2004.

Rousset F. Genepop'007: a complete re-implementation of the Genepop software for Windows and Linux. Molecular Ecology Resources, 8: 103-106. 2008.

Saitou N and Nei M. The neighbor-joining method: a new method for reconstructing phylogenetic trees. Molecular Biology and Evolution, 4: 406-425. 1987.

Tadano R, Nishibori M, Nagasaka N and Tsudzuki M. Assessing genetic diversity and population structure for commercial chicken lines based on forty microsatellite analyses. Poultry Science, 86: 2301-2308. 2007.

Tadano R, Goto N and Tsudzuki M. Genetic differentiation among White Leghorn lines: application of individual-based clustering approaches. Poultry Science, 90: 725-730. 2011.

Takahashi $\mathrm{H}$ and Nakamura A. Genetic diversity and differentiation of the Nagoya breed inferred from microsatellite DNA polymorphisms. Journal of Poultry Science, 44: 135-140. 2007.

Tixier-Boichard M, Bordas A and Rognon X. Characterization and monitoring of poultry genetic resources. World's Poultry Science Journal, 65: 272-285. 2009.

Toro MA, Fernandez J and Caballero A. Molecular characterization of breeds and its use in conservation. Livestock Science, 120: 174-195. 2009.

USDA. GAIN report number: TW6031. pp. 1-2. USDA Foreign Agricultural Service. 2006.

Weir BS. Intraspecific differentiation. In: Molecular systematic (Hillis DM and Moritz C eds.). pp. 124-125. Sinauer Associates. Sunderland, Massachusetts. 1990.

Weir BS and Cockerham CC. Estimating $F$-statistics for the analysis of population structure. Evolution, 38: 1358-1370. 1984. 